\title{
Evaluation of Potential Extracts Antioxydant (Aqueous, Hydro-Ethanolic and Ethanolic) of an Aquatic Plant from the River Djoue (Ledermanniella schlechteri)
}

\author{
Roniche Nguie ${ }^{1,2}$, Tsiba Gouollaly ${ }^{3,4}$, Arnaud W. G. Tamba Sompila ${ }^{1,5,6^{*}}$, J. E. Moussounga1,5,6, \\ M. Gadet Dzondo' ${ }^{1,2,5,6}$, N. P. G. Pambou-Tobi ${ }^{1,5,6}$, P. Diakabana1,2,7, Reyes H. Gampoula ${ }^{1,6}$ \\ ${ }^{1}$ Centre de Recherche et d'Initiation des Projets de Technologie, cité scientifique, route de l'auberge de Gascogne, Brazzaville, \\ Congo \\ ${ }^{2}$ EPRAN-Congo, Pôle d'Excellence en Alimentation et Nutrition, Faculté des Sciences et Techniques, Université Marien \\ NGOUABI, Brazzaville, Congo \\ ${ }^{3}$ Institut national de Recherche en Sciences de la Santé, cité scientifique, route de l'auberge de Gascogne, Brazzaville, Congo \\ ${ }^{4}$ Unité de Chimie du Végétal et de la Vie, FST-UMNG, Brazzaville, Congo \\ ${ }^{5}$ Laboratoire de Bioprocédés alimentaires et médicaux, ENSP-UMNG, Brazzaville, Congo \\ ${ }^{6}$ Ecole Nationale Supérieure Polytechnique (ENSP), Université Marien NGOUABI (UMNG), Brazzaville, Congo \\ ${ }^{7}$ Ecole Supérieure de Technologie des Cataractes, Brazzaville, Congo \\ Email: ^arnaud.wens@gmail.com
}

How to cite this paper: Nguie, R., Gouollaly, T., Tamba Sompila, A.W.G., Moussounga, J.E., Dzondo, M.G., Pambou-Tobi, N.P.G., Diakabana, P. and Gampoula, R.H. (2021) Evaluation of Potential Extracts Antioxydant (Aqueous, Hydro-Ethanolic and Ethanolic) of an Aquatic Plant from the River Djoue (Ledermanniella schlechteri). Open Journal of Applied Sciences, 11, 254-263.

https://doi.org/10.4236/ojapps.2021.113018

Received: January 12, 2021

Accepted: March 12, 2021

Published: March 15, 2021

Copyright $\odot 2021$ by author(s) and Scientific Research Publishing Inc. This work is licensed under the Creative Commons Attribution-NonCommercial International License (CC BY-NC 4.0). http://creativecommons.org/licenses/by-nc/4.0/ (c) (i) $\$$ Open Access

\begin{abstract}
The aim for this present study was to evaluate the antioxidant potential of aqueous extracts (AE), hydro-ethanolic extracts (HE) and ethanolic extracts (EE) obtained from an aquatic plant ( $L$. schlechteri) using a simple and fast method that is the CCM. This method revealed the presence of phenolics and flavonoids at different levels but with higher antioxidant activity in EE compared to AE. Among the two families of antioxidants evaluated, the phenolic compounds were found to be higher on the EE (5.85 mgEAG/MS) followed by the HE (5.06 mgEAG/MS) and less and less important on the AE (3.661 mgEAG/MS). While the less significantly elevated flavonoids showed values of $1.146 \mathrm{mgECa} / \mathrm{MS}$ for $\mathrm{EE}, 0.406 \mathrm{mgECa} / \mathrm{MS}$ for $\mathrm{HE}$ et $0.181 \mathrm{mgECa} / \mathrm{MS}$ for AE. However, the anti-free radical activity was also evaluated. Unlike the antioxidant activity, the ant-free radical activity with a greater IC50 was observed on $\mathrm{AE}$ with a rate of $66.66 \mathrm{mg} / \mathrm{mL}$, then less on the hydro-ethanolic and ethanolic extracts, respectively at levels of $26.15 \mathrm{mg} / \mathrm{mL}$ et $19.18 \mathrm{mg} / \mathrm{mL}$.
\end{abstract}

\section{Keywords}

Evaluation, Antioxidant Potential, Extracts, Aquatic Plant, Ledermanniella schlechteri 


\section{Introduction}

The consumption of vegetables and fruits known as potential sources of antioxidants, is becoming more and more interesting given that human health has become precarious following the appearance of many diseases (cardiovascular, diabetes, cancer) [1]. When the presence of toxic oxygen radicals AOS (active oxygen species) becomes uncontrollable in the body, the weakening of our antioxidant defenses occurs (deficiencies in vitamins and trace elements. A high consumption of fruits and vegetables could have been associated with the decrease in the risk of these diseases in numerous epidemiological studies [2]. Scientific progress has shown that these natural products (vegetables, fruits, etc.) can account for enormous sources of antioxidants making it possible to counteract pathological disorders linked to oxidative stress in the human body. It turns out that this protective effect is based on multiple constituents of these foods (fruits and vegetables) such as fibers, vitamins, minerals and polyphenols [1]. Indeed, total polyphenols are natural compounds widely distributed in the vegetable realm (particularly abundant in fruits, cereals and vegetables); they are increasingly important particularly thanks to their beneficial effects on health [3]. Their role as natural antioxidants is generating a growing interest in preventing and treating cancer, inflammatory and cardiovascular diseases [4].

Ledermanniella schlechteri, one of the vegetables that may have antioxidant potential, is an aquatic plant found in the river Djoué, one of the tributaries of the great Congo River and whose flora has several plant resources. This vegetable highly prized by the population of Brazzaville, especially in the southwest, is commonly called Michiélé. It belongs to the Podostémaceaé family. The vegetable is submerged in water under the rocks of the large tributary of Djoué. This edible plant, little known to the Congolese population, has not yet been the subject of a scientific study.

It is for this reason that we have set ourselves the objective of evaluating the antioxidant potential of three extracts of Michiélé plant by evaluating the contents of polyphenols (total phenols and flavonoids) and subsequently evaluating the anti-radical potentialities of these different plant extracts.

\section{Materials and Methods}

\subsection{Vegetal Materiel}

Michiélé plant was collected in a district in the southwestern part of Brazzaville along the Congo River, particularly under the rocks of its main tributary the Djoué. This aquatic plant was left to dry at room temperature, $25^{\circ} \mathrm{C}$, in the shade for about a week. The dry matter was ground with a device of the IKA-WERKE Gmbh-CO-KG, D-79219 Staufen type, fitted with a sieve with a $0.25 \mathrm{~mm}$ granulometry. The plant was identified by the national herbarium located within the grounds of the National Institute of Research in Exact and Natural sciences (l'Institut national de Recherche en Sciences Exactes et Naturelles IRSEN) of the Ministry of Scientific Research and Technological Innovation (Figure 1). 


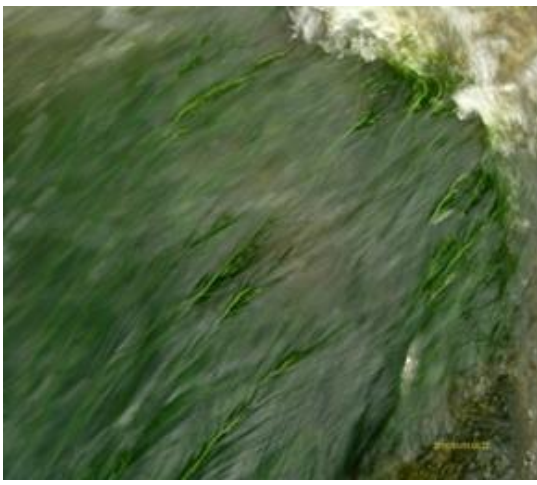

(a)

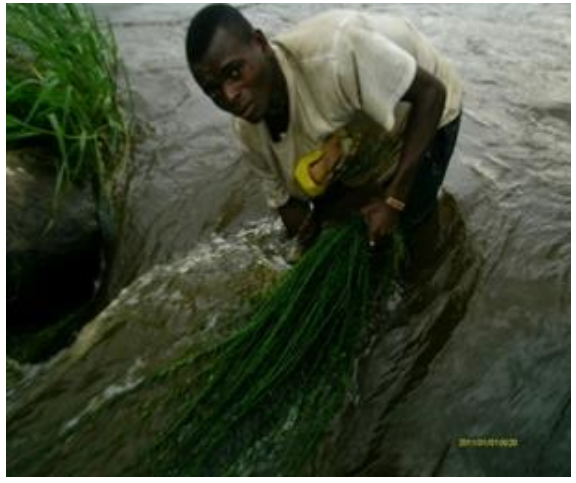

(b)

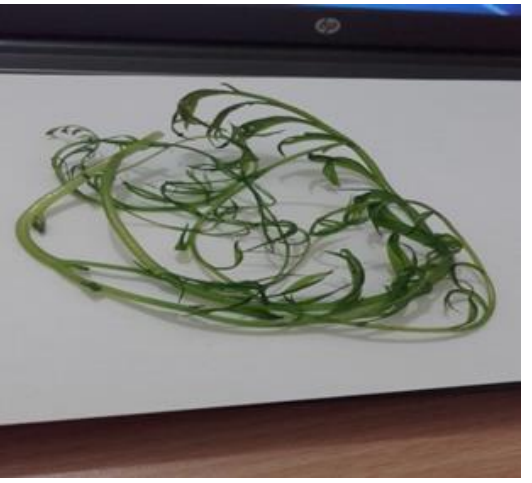

(c)

Figure 1. (a): Michielah's plant in water; (b): Recovery of Michiélé's plant; (c): Part of Michiélés plant.

\subsection{Methods}

\subsubsection{Preparation of Extracts}

The various extracts produced for the numbering of the total poluphenols and flavonoids were obtained by mixing $30 \mathrm{~g}$ of the plant material in $2 \times 150 \mathrm{~mL}$ of different organic solvents, respectively for the preparation of aqueous extracts (AE), hydro-ethanolic extracts (HE) and ethanolic extracts (EE) in the same proportions $50 \%(\mathrm{v} / \mathrm{v})$. The mixture was then macerated by stirring for $48 \mathrm{~h}$, then filtered through filter paper. The filtrate obtained was concentrated to dryness at $50^{\circ} \mathrm{C}$ at reduced pressure, using N-1 rotatory evaporator (Eyela, Tokyo Rikakikal co., Ltd. Japon) and stored in an oven at $25^{\circ} \mathrm{C}$, the kept cool $\left(+4^{\circ} \mathrm{C}\right)$ awaiting analysis.

\subsubsection{Preparation of Dosing Solutions at Different Dilutions}

In a series of glass tubes, mixtures of extract and solvent were mixed either 40 $\mathrm{mg}$ for the ethanolic extract, $80 \mathrm{mg}$ for the hydroethanolic extract and $160 \mathrm{mg}$ for the extract; then $2 \mathrm{~mL}$ of solvent was added (ethanol, water-ethanol and water) in each tube. The solutions were mixed under magnetic stirring for a few moments and the stock solutions were obtained for each extract. From the stock solutions, we also prepared the daughter solutions for each extract by dilution to $1 / 2$. We prepared a total of 4 (S1 to S6) for each extract from which we then obtain 12 daughter solutions. 


\subsubsection{Thin Layer Chromatography Method: TLC}

The quantitative identification of substances with antioxidant activity was carried out according to the "bioautography" method [5] by thin layer chromatography where the antioxidant activity was revealed by DPPH, according to [6]. The CCM was carried out on a 60 F254 silica gel chromatographic plate on a 20 $\mathrm{cm} \times 20 \mathrm{~cm}$ aluminum foil support from Merck.

The CCM was carried out in normal phase on aluminum plates with the solution of ethyl acetate/formic acid/water in the ratio 8/1/1. Le chromatogram obtained was revealed by spraying Nœud's solution ( $0.5 \mathrm{~g}$ of 2 amino diphenyl borinate $+0.5 \mathrm{~g}$ of $\mathrm{PEG}_{400}+100 \mathrm{~mL}$ of ethanol.

The plates were observed under UV-visible and under UV at $366 \mathrm{~nm}$, before and, in some cases, after visualization by the appropriate reagents.

\subsubsection{Polyphenol Analysis}

The total phenol content of the various extracts of the plant of L. schlechteri was determined according to the Folin-Ciocalteu method. For this, $0.1 \mathrm{~mL}$ of each extract (aqueous, hydro-ethanolic and alcoholic) was used; to this mixture was added $0.9 \mathrm{~mL}$ of distilled water followed by $0.9 \mathrm{~mL}$ of the $1 \mathrm{~N}$ Folin-Ciocalteu method. Immediately $0.2 \mathrm{~mL}$ of the sodium carbonate solution was added $\left(\mathrm{Na}_{2} \mathrm{CO}_{3}\right.$ à $20 \%$ ). The resulting mixture was incubated at room temperature of $25^{\circ} \mathrm{C}$ for about 40 minutes protected from light.

The absorbance was measured with a spectrophotometer at $725 \mathrm{~nm}$ against a solution of methanol used as a blank. The results obtained were expressed in $\mathrm{mg}$ gallic acid equivalent per gram of dry matter (EGA/g Ms).

\subsubsection{Total Flavonoïds Analysis}

The total flavonoid content of the various extracts of L. schlechteri was obtained using Aluminum Trichoride $\left(\mathrm{AlCl}_{3}\right)$ [7]. In a $100 \mathrm{~mL}$ flask were successively introduced $250 \mu \mathrm{L}$ of each extract (aqueous, hydro-ethanolic and alcoholic). $1 \mathrm{~mL}$ of distilled water was combined with this solution, $7.5 \mu \mathrm{L}$ of a solution of sodium nitrate $\left(\mathrm{NaNO}_{2}\right.$ at $\left.5 \%\right)$; the mixture was allowed to stand for 5 minutes. Then 75 $\mu \mathrm{l}$ of aluminum trichloride $\left(\mathrm{AlCl}_{3}\right.$ at $\left.10 \%\right)$ was added. After 6 minutes, $500 \mu \mathrm{L}$ of sodium hydroxide $\mathrm{NaOH}$ with a concentration of $1 \mathrm{~N}$ and $2.5 \mathrm{~mL}$ of distilled water were added successively to the mixture.

The absorbance was measured with a UV-visible spectrophotometer at 413 $\mathrm{nm}$ and the results were expressed as $\mathrm{mg}$ catechin equivalent per gram of dry mater (ECa/g Ms).

\subsubsection{Evaluation of the Anti-Radical Activity of the Different Extracts (Method Using DPPH)}

The evaluation of the anti-free radical activity was carried out using $5 \mathrm{~mL}$ of the solution of 1.1-diphenyl-2-picrylhydrazyl (DPPH at $10 \mathrm{mg}$ in $250 \mathrm{~mL}$ of ethanol) and $100 \mu \mathrm{L}$ of each extract diluted at concentration raging from 1.25 to 20 or even $40 \mathrm{mg} / \mathrm{mL}$, all mixed in EDTA type glass tubes. After 30 minutes of incubation in the dark, the anti-free radical activity was measured in a spectrophoto- 
meter at $517 \mathrm{~nm}$ in the dark [8]. The percentage of inhibition was calculated by the following relationship

$$
\begin{aligned}
& \text { Avec D. } \mathrm{O}_{\text {Blanc }}: 0.727 \text {, Avec D. } \mathrm{O}_{\text {Blanc }}: 0.788 \\
& \mathrm{I}=\frac{\mathrm{D} \cdot \mathrm{O}_{\text {blanc }}-\mathrm{D} \cdot \mathrm{O}_{\text {extrait }}}{\mathrm{D} \cdot \mathrm{O}_{\text {blanc }}} \times 100
\end{aligned}
$$

The IC50 parameter (50\% inhibitory concentration) is defined as the concentration of the substrate which causes the loss of $50 \%$ of the activity of DPPH. The antioxidant power is determined so that an amount of the extract of a specific concentration neutralizes $50 \%$ of the DPPH radical. In order to compare the extracts with each other, this index is obtained either by deduction from the curves of the variation in the percentage of inhibition I\% or calculated graphically by the formula for the regression of the percentages of the inhibition as a function of different concentrations of the extracts, tested using the Origine Pro 8 software. The value of the anti-free radical activity, such that $y=50 \%$, corresponds to the IC50 inhibitory concentration of the extract studied [8] [9] [10]. It should be remembered that the lower the value of IC50, the greater the antioxidant activity of the extract [11]. The results expressed in IC50 were deducted from the data presented of the variation in the percentage inhibition I\% depending on the concentration of each extract. It should be remembered that the lower the value of IC50, the greater the antioxidant activity of the extracts [11].

\section{Results and Discussion}

\subsection{Thin-Layer Chromatography}

The chromatographic profile of the hydro-ethanolic extract and the four (04) reference compounds (Quercetin, Rutin, Acide Caffeic Acid and Chlorogenic Acid) obtained after exposure of the plate to the UV-lamp (Figure 2) show a succession of the spots materializing the presence of polyphenolic compounds.

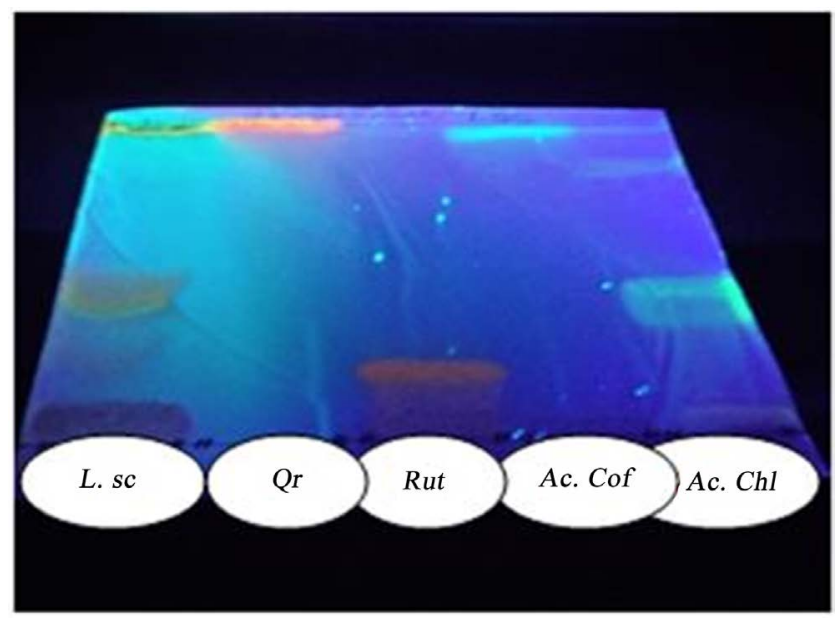

Figure 2. Chromatographic profiles of the hydro-ethanolic extract and some reference compounds. 
Thin layer chromatographic analysis of the hydro-ethanolic extract of $L$. schlechteri showed the presence of a few chemical families. Specific developers were used; the staining of the spots was associated with the presence of a chemical family. On this CCM plate revealed at the node and observed at UV $(365 \mathrm{~nm})$ revealed the blue, bluish white spots which recall the presence of polyphenols, on the other hand, the white, pink, orange and green spots are characteristic of flavonoids. CCM analysis of $L$. schlechteri extracts in Figure 2 revealed the presence of flavonoids, polyphenols. On the CCM plate obtained, the appearance of yellow, yellow-orange fluorescences correspondingto the reference compounds Quercetine ( $Q r)$ and caffeic Acid (AcCaf) is observed. In the middle, yellow and green fluorescences corresponding to the reference compound Chlorogenic Acid (Ac.Chl); and a little downwards an orange fluorescence for the reference compound Rutin (Rut). According to [12] [13], the color fluorescences observed on the various reference compounds ( $Q r, R u t, A c . C a f, A c . C h l)$ are characteristic of flavonoids and polyphenols.

\subsection{Phenols and Flavonoids Content}

The contant of total phenols and flavonoids in the various extracts of Ledermanniella schlechteri (Figure 3) was determined using separately colorimetric methods (Folin-Ciolcateaux and aluminum Trichlorure). The quantitative analysis of polyphenols gives content values of 5.85, 5.06 and $3.66 \mathrm{mgEAG} / \mathrm{MS}$ respectively for the ethanolic, hydro-ethanolic and aqueous extracts and those of the flavonoids in the same order of $1.15,0.41$ and $0.18 \mathrm{mgECa} / \mathrm{MS}$. All the extracts are found to be rich in polyphenols and have low flavonoids. This difference in content between the different compounds can be explained by the fact that total polyphenols include flavonoids and other compounds. It is also observed that the alcoholic extracts are quantitatively richer in these phenolic compounds. According to the literature, alcoholic extracts are the richest in phenolic compounds, their high level of ethanolic and hydro-ethanolic extracts in our plant leads to the conclusion that alcohol remains the best solvent to extract these compounds. This affinity is supported by several studies [14]. This is

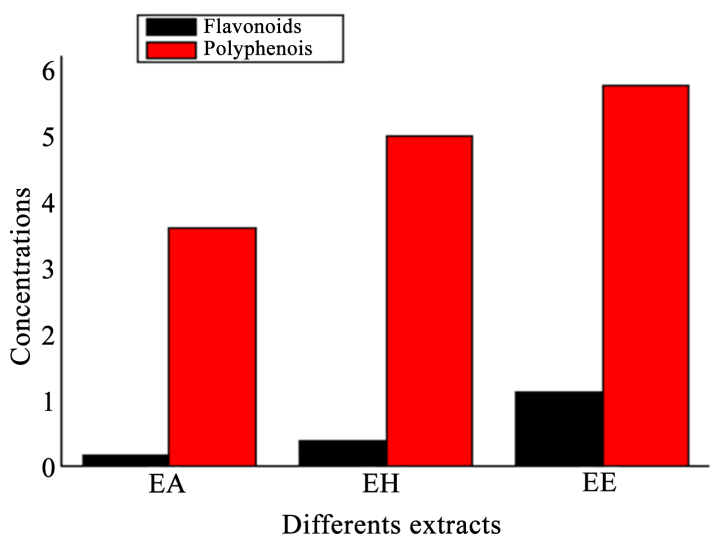

Figure 3. Dosage of total polyphenols and flavonoids in aqueous, hydro-éthanolic and ethanolic extracts. 
due to the ability of alcohol to inhibit the action of polyphenol oxidase which causes the oxidation of polyphenols in plant tissues [15].

The quantitative analysis of total polyphenols and flavonoids shows that the ethanolic (EE) and hydro-ethanolic (HE) extracts are quantitatively richer in total polyphenols and flavonoids than in the aqueous extract (EA). The polyphenol content in the extracts are respectively $5.85 \mathrm{mgECa} / \mathrm{MS}$ for the ethanolic extract (EE), $5.06 \mathrm{mgECa} / \mathrm{MS}$ for the hydro-ethanolic extract (HE) and $3.66 \mathrm{mgECa} / \mathrm{MS}$ for the aqueous extract (AE) against $1.15 \mathrm{mgECa} / \mathrm{MS}$ for the flavonoids for the ethanolic extract (EE), $0.0406 \mathrm{mgECa} / \mathrm{MS}$ for the hydro-ethanolic extract (HE) and $0.18 \mathrm{mgECa} / \mathrm{MS}$ for the aqueous extract (AE). It is found that all the extracts of $L$. schlechteri are rich in polyphenols and have low levels of flavonoids. These differences in content between different compounds can be explained by the facts that total polyphenols include flavonoids and other compounds. It is also noted that the alcoholic extracts are quantitatively richer in phenolic compounds that is to say that this solvent extracts polyphenols better compared to other mixtures. The literature reports that it is in alcoholic extracts that we find more phenolic compounds [14]. The high level of these compounds in the ethanolic and hydro-ethanolic extracts leads us to conclude that alcohol remains the solvent of choice for extracting these compounds. This affinity is supported by [14]. This is due to the ability of alcohole to inhibit the action of polyphenols oxidase which causes the oxidation of polyphenols in plant tissues [15].

It can also be noted that the stationary phase used (polyamide 6-Fluka) made it possible to enrich these extracts with polyphenolic compounds. The high levels of total polyphenols and flavonoids obtained in the present study could be justified by the very clear evidence observed by thin layer chromatography (CCM) and the presence of these metabolites reported by several authors in the plant [16].

\subsection{Anti-Free Radical Activity of the Different Extracts}

\subsubsection{Percent Inhibition of the DPPH Radical}

The results of the anti-free radical activity of the various extracts on DPPH are shown in the series of Tables 1-3. The series of Tables 1-3 shows at a low concentration of $1.25 \mathrm{mg} / \mathrm{ml}$, the ethanolic (EE), hydro-ethanolic (HE) and aqueous (AE) extracts show percentages of reduction of DPPH, respectively $10.73 \%$, $5.09 \%$ and $6.46 \%$ but at high concentrations from $20 \mathrm{mg} / \mathrm{ml}$, we noted in the same order $52.13 \%, 38.24 \%$ and $15 \%$. It is noted that the values of the anti-radica; activity increase according to the concentration in the extracts.

Table 1. Anti-free radical activity of the ethanolic extract of Ledermanniella schlechteri.

\begin{tabular}{cccccc}
\hline \multicolumn{7}{c}{ Ethanolic Extract (EE) } \\
\hline Concentration (mg/ml) & 1.25 & 2.50 & 5 & 10 & 20 \\
Optical density (D.O) & 0.65 & 0.64 & 0.60 & 0.49 & 0.35 \\
Percent inhibition (\%) & 10.73 & 11.55 & 17.05 & 33.01 & 52.13 \\
\hline
\end{tabular}




\subsubsection{0\% Inhibitory Concentrations}

The evaluation of the inhibitory concentration at $50 \%$ of the different extracts (Figure 4) gave $19.18 \mathrm{mg} / \mathrm{mL}$ of the ethanolic extract (EE), $26.15 \mathrm{mg} / \mathrm{mL}$ of the hydro-ethanolic extract ( $\mathrm{HE})$ and $66.66 \mathrm{mg} / \mathrm{mL}$ of the aqueous extract ( $\mathrm{AE}$ ). Based on these results, it was found that the IC50s of the ethanolic (EE) and hydro-ethanolic (HE) extracts are lower compared to that of the aqueous extract (AE). These low values of the 50\% inhibitory concentrations (IC50) of the ethanolic and hydro-ethanolic extracts show that they are endowed with a greater antioxidant power than that of the aqueous extract and this explains why alcohol remains the best solvent for extraction for this study. This strong inhibition of free radicals from ethanolic and hydro-ethanolic extracts (Figure 4) could be justified by their high concentrations of phenolic compounds which are known to be powerful compounds having a reducing power of the free radicals [17] [18].

We can also note that anti-free radical activity is the opposite of anti-oxidant activity. In fact, polyphenolic compounds are reputed to be powerful compounds having a reducing power of free radicals [18].

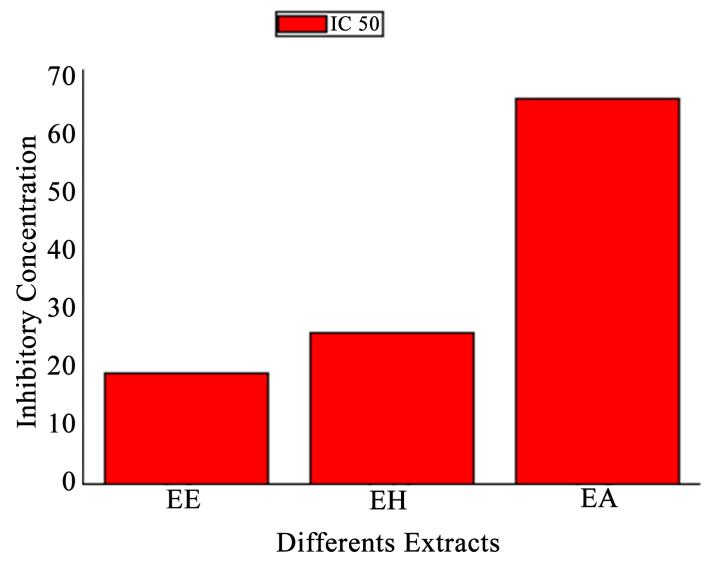

Figure 4. Evaluation of the anti-free radical activity in the different extracts.

Table 2. Anti-free radical activity of the hydro-ethanolic extract of Ledermanniella schlechteri.

\begin{tabular}{ccccccc}
\hline \multicolumn{7}{c}{ Hydro-Ethanolic Extract (HE) } \\
\hline Concentration (mg/ml) & 1.25 & 2.50 & 5 & 10 & 20 & 40 \\
Optical density (D.O) & 0.69 & 0.68 & 0.65 & 0.61 & 0.45 & 0.17 \\
Percent inhibition (\%) & $\mathbf{5 . 0 9}$ & $\mathbf{6 . 3 3}$ & $\mathbf{1 1 . 0 0}$ & $\mathbf{1 5 . 6 8}$ & $\mathbf{3 8 . 2 4}$ & $\mathbf{6 4 . 4 8}$ \\
\hline
\end{tabular}

Table 3. Anti-free radical activity on the aqueous extract of Ledermanniella schlechteri.

\begin{tabular}{ccccccccc}
\hline \multicolumn{7}{c}{ Aqueous Extract (AE) } \\
\hline Concentration (mg/ml) & 1.25 & 2.50 & 5 & 10 & 20 & 40 & 80 \\
Optical density (D.O) & 0.68 & 0.68 & 0.67 & 0.64 & 0.62 & 0.50 & 0.29 \\
Percent inhibition (\%) & 6.46 & 7.15 & 7.84 & 12.65 & 15 & 30 & 60 \\
\hline
\end{tabular}




\section{Conclusion}

The target for this study was met. Evaluation of the antioxidant activity of extracts from this plant by TLC and by the method using DPPH revealed total polyphenols as well as flavonoids. The determination of polyphenols and total flavonoids on the three extracts EE, HE and EA showed that the ethanolic extract (EE) of the Ledermanella schelchterie plant has a high level of polyphenols (5.85 mgEAG/MS) and flavonoids (1.15 mgEAG/MS) totals compare to the other two HE and EA. On the other two extracts, we also note a high content of polyphenonols (5.06 mgEAG/MS) and less of flavonoids (0.46 mgEAG/MS). In general, this plant is rich in polyphenols but also in flavonoids. In addition, they are potentially rich in anti-radical compounds. These results allow us to say that this plant, which is already consumed by the Congolese population, must be popularized to draw a profile of the antioxidant potential that it abounds.

\section{Acknowledgements}

We thank all the managers and colleagues of the laboratories where we carried out our work, may they find here our deepest gratitude.

\section{Conflicts of Interest}

The authors declare no conflicts of interest regarding the publication of this paper.

\section{References}

[1] Favier, A. (2003) Le stress oxidant: Intérêt conceptuel et expérimental dans la compréhension des mécanismes des maladies et potentiel thérapeutique. Mécanismes Biochimiques, 11, 108-115

[2] Rouanet, J.M., Décordé, K., Del Rio, D., Auger, C., Borges, G., Cristol, J.P., Lean, M.E.J. and Crozier, A. (2010) Berry Juices, Teas, Antioxidants and the Prevention of Atherosclerosis in Hamsters. Food Chemistry, 118, 266-271. https://doi.org/10.1016/j.foodchem.2009.04.116

[3] Koechlin-Ramonatxo, C. (2006) Oxygen, Oxidative Stress and Antioxidant Supplementation, or Another Way for Nutrition in Respiratory Diseases. Nutrition Clinique et Métabolique, 20, 165-177. https://doi.org/10.1016/j.nupar.2006.10.178

[4] Vârban, D.I., Duda, M., Vârban, R. and Muntean, S. (2009) Research Concerning the Organic Technology for Satureja hortensis L. Culture. Bulletin of University of Agricultural Sciences and Veterinary Medicine, 66, 225-229.

[5] Gangopadhyay, M., Dewanjee, S., Bhattacharya, N., Khanra, R. and Dua, T.K. (2015) Bioautography and Its Scope in the Field of Natural Product Chemistry, Journal of Pharmaceutical Analysis, 5, 75-84. https://doi.org/10.1016/j.jpha.2014.06.002

[6] Takao, T., Kitatani, F., Watanabe, N., Yagi, A. and Sakata K. (1994) A Simple Screening Method for Antioxidants and Isolation of Seyeral Antioxidants Produced by Marine Bacteria from Fish and Shellfis. Bioscience, Biotechnology, and Biochemistry, 58, 1780-1783. https://doi.org/10.1271/bbb.58.1780

[7] Mansouri, A., Embarek, G., Kokkalou, E. and Kefalas, P. (2005) Phenolic Profile 
and Antioxidant Activity of the Algerian Ripe Date Palm Fruit (Phoenix dactylifera). Food Chemistry, 89, 411-420. https://doi.org/10.1016/j.foodchem.2004.02.051

[8] Mensor, L.L., Menezes, F.S., Leitão, G.G., Reis, A.S., Santos, T.C., Coube, C.S. and Leitão, S.G. (2001) Screening of Brazilian Plant Extracts for Antioxidant Activity by the Use of DPPH Free Radical Method. Phytotherapy Research, 15, 127-130. https://doi.org/10.1002/ptr.687

[9] Sanchez-Moreno, C., Larrauri, J.A. and Saura-Calixto, F. (1998) A Procedure to Measure the Antiradical Efficiency of Polyphenols. Journal of the Science of Food and Agriculture, 76, 270-276. https://doi.org/10.1002/(SICI)1097-0010(199802)76:2<270::AID-JSFA945>3.0.CO;2-9

[10] Nouioua, W. (2012) Thème Biodiversité et Ressources phytogénétiques d'un écosystème forestier "Paeonia mascula (L.) Mill.", Mémoire présenté à la Faculté des Sciences de la nature et la vie Département de Biologie végétale et d'Écologie Pour l'obtention du diplôme de MAGISTER Option: Biodiversité et gestion des écosystèmes.

[11] Popovici, C., Saykova, I. and Tylkowski, B. (2009) Evaluation de l'activité antioxydant des composés phénoliques par la réactivité avec le radical libre DPPH. Revue de Génie Industriel, 4, 25-39.

[12] Markham, K.R. (1982) Technique of Flavonoid Identification. Academic Press, London.

[13] Rizk, A.M. (1982) Constituents of Plants Growing in Qatar. Fitoterapia, 52, 35-42.

[14] Abdille, M., Singh, R., Jayaprakasha, G. and Jena, B. (2005) Antioxidant Activity of the Extracts from Dillenia indica Fruits. Food Chemistry, 90, 891-896. https://doi.org/10.1016/j.foodchem.2004.09.002

[15] Yao, L.H., Jiang, Y.M., Shi, J., Tomas-Barberan, F.A., Datta, N., Singanusong, R. and Chen, S.S. (2004) Flavonoids in Food and Their Health Benefits. Plant Foods for Human Nutrition, 59, 113-122. https://doi.org/10.1007/s11130-004-0049-7

[16] Nsemi, F.M. (2010) Identification de polyphénols, évaluation de leur activité antioxydante et étude de leurs propriétés biologiques. Biologie végétale. Université Paul Verlaine-Metz, Français. NNT: 2010METZ011S.

[17] Bruneton, J. (1993) Pharmacognosie et phytochimie des plantes médicinales. $2^{\text {ème }}$ Edition, Lavoisier Paris, 998.

[18] Huang, W.Y., Cai, Y.Z. and Zhang, Y.B. (2009) Natural Phenolic Compounds from Medicinal Herbs and Dietary Plants: Potential Use for Cancer Prevention. Nutrition and Cancer, 62, 1-20. https://doi.org/10.1080/01635580903191585

\section{Nomenclature}

EGA: Gallic Acid Equivalent

ECa: Catechin Equivalant

L.sc. Ledermanniella schlechteri

Qr. Quercetin

Rut: Rutin

Ac. Caf. Caffeic Acid

Ac.Chl: Chlorogenic Acid 